\title{
A IMPORTÂNCIA DOS ESTUDOS EMPÍRICOS SOBRE OS FENÔMENOS ATMOSFÉRICOS
}

\section{THE IMPORTANCE OF EMPIRICAL SEARCHES ABOUT OF ATMOSPHERIC PHENOMENA}

\author{
Alyson Bueno Francisco ${ }^{1}$ \\ ${ }^{1}$ Universidade Estadual Paulista - UNESP, Pós-doutorando pelo Programa de \\ Pós-Graduação em Geografia e Doutor em Geografia, Presidente Prudente, SP \\ e-mail alysonbueno@gmail.com
}

RESUMO - Este artigo visa apresentar críticas aos mitos sobre os fenômenos atmosféricos, a partir de uma análise da obra Centúria de Nostradamus, de argumentos científicos contra a hipótese do aquecimento global antropogênico e do efeito estufa. A análise dos escritos de Nostradamus pode ser aproveitada diante da contribuição aos avanços de sua época, mas não são aproveitáveis as previsões diante dos avanços científicos com dados empíricos sobre a atmosfera. Os dados empíricos podem ser utilizados no campo científicos para a criação de teorias gerais que podem tornar-se ideológicas e influenciar negativamente a vida das pessoas, como a hipótese da emissão de cloro pelas atividades humanas e o fim da camada de ozônio com a destruição da vida na Terra. A partir dos dados em escala local do clima urbano proposta por Monteiro e das condições da urbanização podemos adotar critérios científicos para nossa percepção sobre o clima e evitar as previsões fora da realidade.

Palavras-chave: Nostradamus; ozônio; previsões; efeito estufa; clima urbano.

Recebido em: 29/04/2018

Revisado em: 18/09/2018

Aprovado em: 18/12/2018
ABSTRACT - This article aims to present criticism of myths about atmospheric phenomena, from an analysis of the book Centurie of Nostradamus, the scientific arguments against the hypothesis of anthropogenic global warming and the greenhouse effect. The analysis of the writings of Nostradamus can be leveraged on the contribution to the progress of your time, but are not usable predictions on scientific advances with empirical data about the atmosphere. The empirical data can be used in the scientific field to the creation of general theories that can become ideological influence negatively the lives of people, as the hypothesis of chlorine by human activities and the end of the layer with the destruction of ozone life on Earth. From the data in local urban climate proposed for Monteiro and conditions of urbanization can adopt scientific criteria for our perception about the weather and avoid unrealistic expectations.

Keywords: Nostradamus; ozone; previsions; greenhouse effect; urban climate 


\section{INTRODUÇÃO}

A previsão dos acontecimentos futuros é um dos assuntos da humanidade que mais gera discussões pelo fato de que o tempo futuro ainda irá acontecer, mas diante do conhecimento sobre o que ocorreu no passado e como os fenômenos ocorrem no presente, é possível através de conhecimento científico a realização de previsões.

Aristóteles (384 a.C. - 322 a.C.) foi um dos filósofos que mais influenciaram $\mathrm{O}$ pensamento do Mundo Ocidental, e apresentou na obra Meterologica, escrita em 340 a.C., os fenômenos atmosféricos como a formação das nuvens e das precipitações pluviais, os ventos, a dinâmica climática, raios e trovões, fenômenos luminosos do céu e furacões (NEVES; GALLARDO; VECCHIA, 2017).

A Meteorologia é uma ciência que analisa os fenômenos atmosféricos, através dos dados das estações meteorológicas, do conhecimento científico da dinâmica da atmosfera terrestre e da probabilidade estatística pode criar previsões para os próximos dias e aconselhar a população e aos órgãos públicos sobre os riscos apresentados pela dinâmica do tempo meteorológico. Nas últimas décadas, o avanço das tecnologias da comunicação e da informação favoreceu a disponibilidade de informações em tempo real na divulgação dos dados meteorológicos e a possibilidade da população ter acesso aos resultados do monitoramento da atmosfera terrestre.

Apesar de todos os avanços neste campo do saber, os fenômenos atmosféricos são dinâmicos e dependendo da escala temporal podem ser imprevisíveis. No entanto, a humanidade avançou no planejamento e na busca de evitar desastres naturais através do monitoramento dos fenômenos atmosféricos, sendo que isto depende da coleta de dados através das estações meteorológicas, radares e satélites meteorológicos. As informações espaciais sobre a dinâmica dos fenômenos atmosféricos é estudada pelos geógrafos através da análise temporal acumulada dos dados e da Cartografia através da Climatologia Geográfica.

Historicamente, a previsão dos acontecimentos futuros é algo que intrigava os faraós que consultavam os sacerdotes egípcios antes de qualquer batalha. Os sacerdotes egípcios observavam o tempo, os astros e até vísceras de animais para orientar os faraós sobre os resultados futuros nas batalhas. Durante muitos séculos, os monarcas consultavam pessoas que eram consideradas videntes, pelo fato de acreditarem na previsão dos destinos a partir de forças sobrenaturais. No entanto, alguns alquimistas, considerados videntes, se apoiavam nas análises das movimentações dos astros e estrelas para realizarem suas futurologias.

No século XVI, na França viveu Miquel de Nostradame (1503-1566), conhecido como Nostradamus. Este francês foi alquimista, apotecário e médico, sendo um dos principais conselheiros de Catarina de Médici (1519-1589) e de reis franceses pelo seu conhecimento astrológico e estratégico. Nostradamus viveu numa época quando a peste bubônica ainda assolava parte da população europeia, eram raros os instrumentos astronômicos para se observar o céu, se havia muito preconceito em relação à Química para se produzir medicamentos e a perseguição religiosa pela Inquisição.

Nos tempos contemporâneos, as obras de Nostradamus são interpretadas por aproveitadores do mito do fim dos tempos, ao considerarem que este alquimista e médico fosse um profeta apocalíptico.

Apesar da obra Centúrias de Nostradamus ter a presença de inúmeras simbologias e um cenário sombrio sobre o perigo de fome, guerras e demais males na época de Nostradamus (século XVI), neste artigo busca-se uma análise científica destes elementos astrológicos, astronômicos e geográficos da obra Centúrias. 


\section{ANÁLISE CIENTÍFICA DE TRECHOS DA OBRA CENTÚRIAS}

A obra Centúrias é composta de dez conjuntos de cem quadras de versos cada conjunto, totalizando mil quadras de versos. A obra foi publicada na cidade de Salon na França em 1555.

No prefácio da obra, Nostradamus (2003) apresenta que suas profecias são resultado da revelação dos mistérios divinos através da interpretação dos movimentos de planetas:

God's mysteries are incomprehensible and the power to influence events is bound up with the great expanse of natural knowledge, having its nearest most immediate origin in free will and describing future events [...] things are revealed by the planetary movements (NOSTRADAMUS, 2003, p. 04) [Tradução: Os mistérios de Deus são incompreensíveis e a força da influência dos eventos está vinculada à grande expansão do conhecimento natural, tendo sua origem mais próxima das descrições dos eventos futuros [...] coisas são reveladas pelos movimentos planetários].

Diante das possíveis perseguições religiosas que Nostradamus poderia ter sofrido em sua época, este autor considera que escreveu suas profecias com simbologias e não obedeceu uma sequência lógica do tempo em seus escritos, mas salienta que num futuro com o avanço do conhecimento, os leitores iriam compreender esta sequência dos fatos:

[...] while experiencing these inevitable events, how I have listed others in clearer language, so that despite their obscurities these things shall be understood: When the time comes for the removal of ignorance, the matter will be clearer still" (NOSTRADAMUS, 2003, p. 07). [Tradução: enquanto presenciamos eventos inevitáveis, que listei vários em linguagem clara, e que apesar dessa obscuridade, esses eventos precisam ser compreendidos: Ao chegar o tempo do fim da ignorância, a compreensão ficará mais clara.

Uma análise metodológica e filosófica dos escritos de Nostradamus nos leva a considerar que este personagem da História interpretava o mundo considerando a importância da luz da natureza humana, ou seja, nós seres humanos temos a capacidade através de nossa inteligência de perceber os fenômenos naturais e realizarmos previsões futuras pela própria lógica dos acontecimentos e das marcas presentes na paisagem.

No caso de Nostradamus, a análise do movimento dos astros foi seu apoio na elaboração das previsões, juntamente com a ocorrência dos problemas enfrentados em sua época. $O$ autor afirma:

[...] the light of human nature makes the philosophers so sure of themselves that with the principles of the first cause they reach the loftiest doctrines and the deepest abysses. But my son, lest I venture too far for your future perception (NOSTRADAMUS, 2003, p. 05) [Tradução: a luz da natureza humana produzida pelos filósofos, tão segura de si, atinge os princípios da causa primeira e também os mais profundos abismos. No entanto, não me estendo muito em sua percepção futura].

Sobre os fenômenos meteorológicos, Nostradamus (2003) apresenta uma previsão a partir dos astros, da existência de períodos de pouca precipitação (secas):

[...] the year that Saturn and Mars are equal fiery. The air very dry parched long meteor: Through secret fires a great place blazing from burning heat, little rain, warm wind, wars, incursions (NOSTRADAMUS, 2003, p. 134). [Tradução: no ano em que Saturno e Marte são próximos. 0 grande meteoro resseca o ar na escuridão: Através do fogo aparecem chamas com muito calor, secas, pouco vento, guerras e incursões]. 
No entanto, a dinâmica da natureza sem a interferência antrópica já evidencia a existência de climas desérticos e semiáridos, cuja ampliação das áreas desertificadas ainda é analisada nos tempos atuais pelos cientistas do clima.

Outro fenômeno meteorológico apresentado por Nostradamus é o aumento da temperatura no verão na Europa, conforme afirma: "put in chains, behind a strong cable, in the year that Mars, Venus and Sun are in conjunction in summer" (NOSTRADAMUS, 2003, p. 140); [Tradução: ocorrem fortes tempestades no ano de proximidade entre Marte, Vênus e o Sol numa conjunção durante o verão].

Apesar das últimas décadas terem sido notadas altas temperaturas no verão europeu, os indicadores históricos apontam a existência de temperaturas superiores durante a Idade Medieval pela colonização do Ártico pelos dinamarqueses.

A respeito da insolação e das altas temperaturas nos trópicos, Nostradamus (2003, p. 191) afirma: "near the Bear and close to the white wool, Aries, Taurus, Cancer, Leo, Virgo, Mars, Jupiter, the Sun will burn a great plain"; [Tradução: durante a proximidade das constelações Urso e Anã Branca, Áries, Touro, Câncer, Leão, Virgem, planetas Marte e Jupiter e o Sol, irá ocorrer seca numa grande planície].

Entretanto, os índices de insolação, apesar de serem evidenciados pela ampliação dos casos de câncer de pele nos humanos e os resultados da produção de energia elétrica de fonte solar, são muito pouco estudados especificamente pela Meteorologia. Esta escassez de pesquisas sobre os altos índices de insolação nas regiões tropicais, evidenciados naturalmente pelos movimentos de translação da Terra e a inclinação axial, ainda carecem de dados sobre a radiação emitida pelas erupções solares.

A maritimidade é um elemento importante para a compreensão da dinâmica atmosférica, visto que a maior parte da superfície terrestre é composta pelos oceanos. Nostradamus (2003) traz alguns elementos importantes sobre dinâmica das águas marítimas, os ventos e as estações do ano: "the great city of the maritime Ocean, surrounded by a crystalline swamp: in the winter solstice and the spring, it will be tried by frightful wind" (NOSTRADAMUS, 2003, p. 279) [Tradução: a grande cidade do litoral será inundada no solstício de inverno e primavera, sofrendo a ação do vento forte].

Ao vier a maior parte de sua vida na região de Bordeaux na França, Nostradamus presenciou alguns abalos sísmicos e consequentemente relacionou os riscos destes abalos no futuro. Em relação às atividades sísmicas, Nostradamus (2003) apresenta elementos da astrologia, ao se referir ao planeta Mercúrio, e da mitologia grega (Hércules) para mencionar algo natural nas áreas de convergência das placas tectônicas, o fato de "tremer a terra": "the great Mercury of Hercules fleur-de-lys, causing to tremble lands, sea and country" (NOSTRADAMUS, 2003, p. 323) [Tradução: a influência de Mercúrio causará terremotos e maremotos].

O contexto histórico de Nostradamus apresentava uma tímida evolução da Ciência, visto que os principais pensadores da Idade Moderna, como: Galileu Galilei (1564-1642), Nicolau Copérnico (1473-1543) e René Descartes (1596-1650); ainda estavam nascendo e difundindo suas ideias. Assim, o misticismo ainda era presente nos escritos científicos, mas a criatividade e a ousadia dos alquimistas, incluindo Nostradamus, que facilitaram o desenvolvimento da Ciência Moderna dotada de racionalidade e inovação tecnológica.

No entanto, considera-se que estes cientistas do século XVI não possuíam dados suficientes para realizar as previsões, cuja situação só foi modificada com as tecnologias de monitoramento em tempo real na segunda metade do século $X X$. 


\section{OS MITOS DO BURACO DA CAMADA DE OZÔNIO E DO EFEITO ESTUFA}

A hipótese da existência do buraco da camada de ozônio sobre a atmosfera da Antártida, supostamente induzido pela emissão do gás clorofluorcarbono (CFC) foi criada a partir de dados do satélite Nimbus 7, entre 1980 e 1984, pelo pesquisador britânico J. B. Farman e a hipótese elaborada por Molina e Rowland de existência de cloro na estratosfera devida produção de CFC pelas atividades antrópicas (FELÍCIO; ONÇA, 2012).

A respeito do gás ozônio (O3), sua formação ocorre na base da estratosfera necessitando de energia da radiação ultravioleta para desestabilizar o oxigênio molecular, que compõe aproximadamente 21\% da atmosfera terrestre. Quando o ozônio forma-se, seu tempo de vida na atmosfera dinâmica é muito curto. Para Felício e Onça (2012, p. 05): “a maior parte da concentração de nuvens ozônicas que se formam e desaparecem com incrivel rapidez. Assim, não existe a tal 'camada de ozônio', mas sim este setor de maior probabilidade de se observar a sua formação". Logo, o ozônio não forma uma "camada" na baixa estratosfera, cuja temperatura da estratosfera diminui de cima para baixo, atingindo aproximadamente $-82^{\circ} \mathrm{C}$ na noite polar.

Sobre a emissão de cloro na atmosfera, de acordo com Felício e Onça (2012), a produção natural de cloro emitida pelos oceanos e vulcões supera em $82 \mathrm{mil}$ vezes a emissão produzida pelos aerossóis contendo clorofluorcarbono em sua composição. Felício e Onça (2012) também ressalvam que um único vulcão do monte Erebus lança na atmosfera uma quantidade de cloro 58,4 vezes maior do que todas as atividades humanas em um ano.

Nosso raciocínio não é para inocentar a poluição gerada pelas atividades industriais, que emitem vários gases contaminantes na atmosfera principalmente das grandes cidades, mas sim questionar a cobrança feita pelos países ricos aos países em desenvolvimento para reduzirem seu parque industrial e assumirem a culpa pelo suposto aquecimento global antropogênico.

A hipótese do aquecimento global antropogênico foi apoiada na concepção do chamado "efeito estufa", considerando que devido atividades humanas desde a Revolução Industrial a concentração global de $\mathrm{CO}_{2}$ na atmosfera teria provocado um aumento da temperatura média global nas últimas décadas. No entanto, os cientistas precisam questionar a origem dos dados desta concentração de $\mathrm{CO}_{2}$.

De acordo com Ayoade (1996), apenas $0,038 \%$ da atmosfera atual é composta por dióxido de carbono, sendo um gás importante para o desenvolvimento dos vegetais. $\mathrm{O}$ gás oxigênio (02) que atualmente forma aproximadamente $21 \%$ da atmosfera terrestre, já chegou a compor $35 \%$ desta a cerca de 300 milhões de anos A.P.

Os norte-americanos desenvolveram centros de pesquisa importantes no Estado do Havaí e realizam monitoramentos dos fenômenos atmosféricos e astronômicos devido argumento de isolamento do arquipélago pela localização no Oceano Pacífico. O argumento de isolamento do Havaí defende a hipótese de que esta região do planeta não é influenciada pela poluição gerada pelos centros industriais e que os elementos presentes na atmosfera do arquipélago seriam resultado do comportamento médio no planeta.

De acordo com Conti e Furlan (2005), a concentração de $\mathrm{CO}_{2}$ em Mauna Loa, no Havaí, passou de 315 ppm em 1960 para 350 ppm em 1990. No entanto, os estudos vulcânicos comprovam que os vulcões emitem vários gases em suas erupções, incluindo o dióxido de carbono e o vapor d'água. Além disso, o arquipélago do Havaí é originário de um hotpoint, ou seja, uma espécie de "válvula de escape" das células de convecção do manto terrestre com inúmeros vulcões ativos nas últimas centenas de anos.

Logo, é questionável o ato dos pesquisadores tirarem conclusões sobre o aumento de $\mathrm{CO}_{2}$ na atmosfera terrestre a 
partir de dados restritos a uma região vulcânica e ainda considerarem que esta concentração de $\mathrm{CO}_{2}$ tenha origem antrópica. Nosso intuito não é inocentar a poluição nas grandes cidades, nem a destruição das florestas com a queima de biomassa, mas questionar o argumento de que o aumento das temperaturas médias em determinadas regiões do planeta fosse apenas justificado pela ação antrópica e os modelos catastróficos gerados para o cenário futuro.

\section{A ANÁLISE RÍTMICA DE MONTEIRO E AS OBSERVAÇÕES METEOROLÓGICAS}

Os estudos de Climatologia Geográfica a partir do professor Carlos Augusto de Figueiredo Monteiro consideraram a importância da interpretação do clima através da análise rítmica, superando as concepções estatísticas das médias dos tipos de tempo. De acordo com Monteiro (1999, p. 09):

o paradigma da 'análise rítmica',
malgrado às limitações de
abordagem estatística
generalizada mas compensadas
pela amostra dinâmica de
'padrões' extremos e habituais,
foi capaz de ensejar compreensão
geograficamente mais válida do
que aquela abordagem calcada
em 'estados médios' e propostas
de regionalização por valores
indecimétricos a partir do local
para o geral.

Para Monteiro (1999), a visão sintética de clima advém do "ritmo" de sucessão dos tipos de tempo, sendo a análise do clima resultante da percepção dos regimes, que são observações feitas os elementos atmosféricos (pressão, temperatura, umidade, precipitações, ventos, etc.). Este renomado geógrafo, considerou que sua proposta metodológica da análise rítmica na perspectiva geográfica foi herança da Meteorologia Dinâmica existente nos países escandinavos (MONTEIRO, 1999).

Neste sentido, a interpretação do clima precisa partir da observação meteorológica e depende da qualidade da observação. Atualmente, a rede de estações meteorológicas garante a coleta dos dados e o monitoramento contínuo da atmosfera para posterior análise geográfica sobre as condições do clima, evitando alarmismos.

Monteiro (1999) apresenta as escalas geográficas na análise rítmica do clima: "esta ideia de diversificar (zonal), organizar (regional) e especializar (local) na definição (geográfica) dos climas parece-me fundamental" (MONTEIRO, 1999, p. 25-26). Este autor considera a importância da escala local na observação dos fenômenos meteorológicos:

Dentro os conjuntos regionais,
onde o ritmo aponta a
solidariedade há inúmeros
elementos 'locais'. Note-se que
nesta escala é que se principia a
própria tarefa de observação
meteorológica, cuja 'rede de
observação' é um conjunto
composto por vários 'pontos', de
cuja densidade e regularidade de
espaçamento no âmbito da 'rede'
dependem a eficiência e
qualidade da observação
(MONTEIRO, 1999, p. 25).

No contexto atual de inúmeros eventos meteorológicos considerados excepcionais apresentados pelos meios de comunicação são fundamentais as análises climáticas a partir dos dados empíricos dos fenômenos meteorológicos para evitar o mito de fim dos tempos.

\section{A CLIMATOLOGIA URBANA E OS DADOS EMPÍRICOS METEOROLÓGICOS}

A maioria das estações meteorológicas está localizada nas áreas urbanas. Este fator geográfico de localização dos dados coletados sobre a dinâmica meteorológica nos leva a pensar como as edificações, o asfalto e a ausência de árvores influenciam na termodinâmica e na escala local do clima.

A partir das trocas de energia entre 0 ar e os materiais das edificações e infraestrutura urbana, o calor específico 
destes materiais e a ausência de umidade pela falta de arborização de vários setores de uma cidade induzem na presença de altas temperaturas, principalmente no período vespertino.

Para Mendonça e Monteiro (2003) existem os canais de percepção humana para identificar os fenômenos do clima urbano: conforto térmico, qualidade do ar e meteoros do impacto. O conforto térmico é "um filtro perceptivo bastante significativo, pois afeta a todos permanentemente" (MENDONÇA; MONTEIRO, 2003, p. 24). Neste sentido, a percepção humana, dependendo das condições culturais de vestimentas, metabolismo corporal e prática laboral pode levar a interpretação de sensação térmica elevada acima das condições do ambiente. No caso das cidades de clima tropical, existência de edificações com telhados de metais como o zinco e loteamentos urbanos sem arborização torna o desconforto térmico mais notável e a sensação de um possível futuro em condições ainda piores de habitação e sobrevivência.

A respeito do canal de percepção de meteoros de impacto, a ocorrência de inundações durante o verão nas cidades de clima tropical é decorrente principalmente pela falta de planejamento urbano que permitiu a ocupação inadequada de antigas várzeas (planícies de inundação) e falta de sistema de drenagem urbana para direcionar de forma sustentável as águas pluviais.

Apesar dos riscos de inundações, enchentes e deslizamentos decorrentes da falta de planejamento urbano que considerasse os aspectos climáticos e geomorfológicos, o avanço tecnológico da Meteorologia e dos meios de comunicação favoreceu a divulgação do monitoramento dos fenômenos meteorológicos. A previsão do tempo meteorológico tornou-se parte do cotidiano da população e cada vez mais os meios de comunicação divulgam os dados meteorológicos e apresentam dados de outras épocas que tiveram temperaturas máximas superiores ou mínimas inferiores aos chamados eventos extremos, que ocorrem, dependendo da percepção humana e da escala de análise, com mais frequência nos últimos anos.

\section{CONSIDERAÇÕES FINAIS}

O mito do fim dos tempos foi argumentado em várias épocas da História através dos fenômenos atmosféricos e astronômicos que não eram possíveis de serem explicados com fundamentação científica. No entanto, com os avanços das Ciências da Natureza, desde a revolução científica do século XVI que rompeu com os misticismos pela aplicação dos procedimentos empíricos, a humanidade passou a compreender e interpretar adequadamente os fenômenos atmosféricos e os avanços recentes favoreceu a possibilidade de previsões meteorológicas cada vez mais precisas.

As escalas geográficas de compreensão da dinâmica dos processos naturais são fundamentais para estudarmos mais a fundo sobre o que ocorreu no passado e através dos dados empíricos precisos no tempo presente favorece nossa melhor compreensão dos processos naturais. A ação antrópica ocorre com as mudanças na cobertura da terra e na densidade do espaço urbano, provocando alterações no clima local das cidades. No entanto, estas alterações não podem ser interpretadas como globais.

Os fenômenos regionais como a oscilação ENOS (El Niño e La Niña) que afeta os climas em diversas áreas do planeta, ainda são investigados pelos cientistas e não é possível sustentar a hipótese de causa antrópica. As inundações decorrentes do acúmulo de águas pluviais nos períodos de chuvas concentradas são resultantes da falta de planejamento nas cidades com a ocupação irregular de planícies de inundação dos cursos d'água.

A Geografia é uma ciência consolidada através da análise espacial e temporal dos fenômenos naturais e suas relações escalares com a interferência humana na natureza. Diante destes 
conhecimentos científicos, o geógrafo atua no planejamento municipal para orientar os políticos a fim de evitar a ocupação urbana de áreas inadequadas e os futuros problemas ambientais.

\section{REFERÊNCIAS}

AYOADE, J. O. Introdução à climatologia para os trópicos. 4.ed. Rio de Janeiro: Bertrand Brasil, 1996.

CONTI, J. B.; FURLAN, S. A. Geoecologia: o clima, os solos e a biota. In: ROSS, J. L. S. (org.) Geografia do Brasil. 5.ed. São Paulo: Edusp, 2005. p. 67-208

FELÍCIO, R. A.; ONÇA, D. S. Os mitos sobre o ozônio: um resgate das origens da discussão. Fórum Ambiental da Alta Paulista, v. 08, n. 08, p. 01-26, 2012. https://doi.org/10.17271/198008278820123 $\underline{40}$

MENDONÇA, F.; MONTEIRO, C. A. F. Clima urbano. São Paulo: Contexto, 2003.

MONTEIRO, C. A. F. O estudo geográfico do clima. Cadernos Geográficos, São Paulo, n.01, 1999.

NEVES, G. Z. F.; GALLARDO, N. P.; VECCHIA, F. A. S. A Short Critical History on the development of Meteorology and Climatology. Climate, n. 23, v. 05, p. 01-17, 2017. https://doi.org/10.3390/cli5010023

NOSTRADAMUS, M. Centuries. London: Arcanaeum, 2003. 